\title{
Foreign students' learning strategies of Malay language: extralinguistics perspective
}

\begin{abstract}
This study focuses on the formal and informal learning strategies of foreign students in learning the Malay language. The Language Learning Strategy Model by Mohamed Amin Embi (2000) and quantitative analysis have been applied to identify the relationship between the learning strategies and the extralinguistic factors. The research sample comprised of 114 foreign students at one of the private universities in Malaysia who had followed the National Language (B) classes (Malay Language) for 14 weeks. From the 59 strategies listed in the questionnaire, it was discovered that the strategy most preferred and practised formally is 'students giving full attention while the teacher is teaching'. This was followed by 'students will listen carefully to the way the teacher speaks in the Malay language' and 'students will participate in the activities prepared by the teacher'. Meanwhile for the informal strategy, 'students will try to repeat the vocabulary loudly during revision, so that it is easy for them to remember the words' was most favoured. The study reveals that foreign students are relatively passive and depending a lot on the instructors in the mastery of the learning strategies. They are more suited to learn Malay language in formal environments as a result of limited opportunities of exposure to social activities. As such, instructors play the important role to guide, to motivate and to support the learning process among foreign students.
\end{abstract}

Keyword: Learning strategies; Malay language; Foreign students; Foreign language; Mastery process; Extralinguistic perspective; Formal context and informal context 